\title{
Effect of COVID-19 on the Treatment of Infections by Community Pharmacists in Nigeria
}

\author{
Edidiong Orok ${ }^{1}$, Success David ${ }^{2}$, Chiemezie Ibegwan $^{3}$ \\ ${ }^{1}$ Department of Clinical Pharmacy and Pharmacy Administration \\ University of Ibadan, Nigeria, West Africa \\ ${ }^{2}$ Faculty of Pharmacy, University of Nigeria, Nsukka, West Africa \\ ${ }^{3}$ Faculty of Pharmacy, University of Lagos, Nigeria, West Africa
}

\begin{abstract}
COVID-19 has had tremendous effects on different aspects of health care. Patients have been one of the most affected since the pandemic has limited their access to healthcare everywhere in the world including Nigeria. Reduced access to healthcare services in hospitals has caused an increase in the number of patient visits to the community pharmacies. This study was designed to evaluate the effect of the COVID-19 pandemic on the treatment of infections by community pharmacists. This study was a prospective cross-sectional study that was carried out among community pharmacists working in community pharmacies in Ibadan, Oyo state and Uyo, Akwa Ibom state due to the recent rise in COVID-19 cases from July until August 2020. Data was collected through a pre-tested online questionnaire which was sent to the pharmacists upon provision of consent after the purpose of the study was explained. A total of one hundred and twenty two pharmacists consented to participate in this study out of which $65(53.3 \%)$ were female. Malaria (81, 66.4\%), respiratory tract infections $(40,32.8 \%)$ and sexually transmitted infections $(1,0.8 \%)$ were identified as infections with the highest frequency by the community pharmacists, while more than $96 \%$ (118) pharmacists reported that COVID-19 has affected the way they manage or treat other infections seen in their pharmacy. This study shows that the COVID-19 pandemic has affected the way community pharmacists treat other infections in the community pharmacy setting. More studies are needed to explore the specific nature of this effect on specific infections.
\end{abstract}

Keywords: COVID-19, Community Pharmacists, Nigeria, Infections, Treatment

\section{Introduction}

There has been a tremendous decline in the public health, economy and social system of the globe due to the unprecedented widespread of Corona Virus Disease-2019 (COVID-19). ${ }^{1}$ COVID-19 has been documented to affect all ages and is severe amongst patients with other underlying disease condition such as diabetes, cancer, and cardiovascular disease. ${ }^{2,3}$ The widespread of this pandemic has led to an increase in mental health issues and psychological distress globally. ${ }^{4-6}$ The disruption in the economic activities, because of strict pandemic measures such as lockdown of companies and market places, has affected daily activity and livelihood of

Corresponding author: Edidiong Orok. Department of Clinical Pharmacy and Pharmacy Administration, University of Ibadan. Email: pharmorok@gmail.com

Received: 28 August 2020. Revised: 8 December 2020 . Published: 31 December 2020 
the people which has posed a negative effect on their mental health. ${ }^{6}$

The onset of the COVID-19 pandemic has brought about a paradigm shift in the healthcare system. More focus is now channeled towards the fight against COVID-19 in an attempt to flatten the infection curve. ${ }^{7}$ COVID-19 has had an effect on patient access to healthcare due to increase in cost of healthcare services. This increase has predictably had a negative impact on patients of low socioeconomic status causing more patients to present to the community pharmacies for their healthcare needs. ${ }^{8}$

In the community pharmacies, pharmacists are easily accessible for information on minor ailments including urinary tract infections, respiratory tract infections and malaria ${ }^{9}$ and are seen as the first point of contact with patients for health advice and medication access during the COVID-19 pandemic. $^{10}$ COVID-19 is associated with symptoms such as dry cough, fever, and headache ${ }^{11}$ and these symptoms are common with infections usually managed in the community pharmacies. This study aims to evaluate the effect of COVID-19 on the treatment of other infections by community pharmacists.

\section{Methods}

\section{Research Ethic}

The study protocol was approved by the University of Ibadan/University College Hospital Ethics Committee, with approval number UI/EC/20/0197. The study was conducted in accordance with the ethical standards as laid down in the 1964 Declaration of Helsinki and its later amendments. ${ }^{12}$

\section{Study Design}

This study was a prospective cross-sectional study. The study was carried out from July until August 2020.

\section{Study Site}

The study was conducted in Ibadan, Oyo state and Uyo, Akwa Ibom state. The choice of this study area was informed based on convenience and due to the rising COVID-19 cases in the areas according to NCDC reports in July. ${ }^{13}$

\section{Study Population}

The study was carried out among community pharmacists working in community pharmacies in Ibadan, Oyo state and in Uyo metropolis, Akwa Ibom state. Uyo is the capital of Akwa Ibom state, southeastern Nigeria. Uyo lies on the road from Oron to Ikot Ekpene with an estimated population of $440,000 .{ }^{14}$ Ibadan is located in southwestern Nigeria in the southeastern part of Oyo state at about 119 kilometers northeast of Lagos. The city covers a total area of 3,080 square kilometers. There are eleven Local Governments in the Ibadan Metropolitan area consisting of five urban local governments in the city and six semi-urban local governments. ${ }^{15}$

\section{Sample Size Determination and Sampling technique}

Sampling of the pharmacies was done in two different locations, Uyo Metropolis $(\mathrm{n}=108)$ and Ibadan Metropolis $(\mathrm{n}=110)$.

\section{Inclusion criteria}

Pharmacists that have been working at the pharmacy community for minimum a year and agreed to participate in the study were included in the study.

\section{Exclusion criteria}

Undergraduate students on industrial attachment and National Youth Service Corp pharmacists, who were also present in the community pharmacies visited, were excluded from the study. 


\section{Instrument for Data Collection}

Data was collected through an online questionnaire carefully designed and administered to the respondents. The questionnaire contained three sections. The first section measured the demographics of the pharmacists, the second section measured the profile of infections treated by the pharmacists in each pharmacy and the third section measured the effect of COVID-19 on the management of infections in the pharmacy. The third section was measured using a five point Likert scale where the score of 5 was assigned to strongly agree and 1 for strongly disagree. The questionnaire used in this study has been added as study supplementary material.

\section{Validation of Data Collection Instrument}

The questionnaire used in this study was validated using face validity among lecturers in the department of Clinical Pharmacy and Pharmacy administration, University of Ibadan with community pharmacy experience. The reliability of the questionnaire was also tested via a pre-test in 10 community pharmacies that were not included in the main study and the Cronbach alpha value obtained from the pre-test was 0.72 .

\section{Study protocol and Informed consent}

Each pharmacy was approached and the purpose of the study was explained to the pharmacists. The consent of each pharmacist was sought for inclusion in the study. The pharmacists who met the inclusion criteria and consented to the study were sent the online questionnaire and asked to fill immediately while the pharmacists that declined to participate were excluded from the study. After filling the questionnaire the pharmacists were sent an appreciation email which was generated automatically after the questionnaire was submitted.

\section{Data Analysis}

Age and years of experience of the community pharmacists were expressed as mean and standard deviation. Gender, additional qualifications and other categorical variables were expressed as percentages and proportions. All data analysis was carried out using SPSS Software (IBM SPSS for Windows. Version 25.0, Armonk, NY: IBM Corp). The data written \pm SD Differences were considered significant at $\mathrm{P}<0.05$.

\section{Results and Discussion}

Socio-demographics of the community pharmacists

The final sample size for the study was determined using the number of community pharmacists that consented to participate in the study and met the inclusion criteria used in the study. The total number of pharmacists that gave consent to participate in the study from the two states were 122 pharmacists representing approximately 56\% response rate. Sixty five $(53.3 \%)$ participants were female while $72 \quad(59.0 \%)$ pharmacists practiced in Oyo state. Seventy one $(59.0 \%)$ community pharmacists had B.Pharm degree only while the mean age of the pharmacists was 31.05 years \pm 3.216 (range 23-38 years). More details are provided in Table 1.

Infections managed by the community pharmacists

In this study, the community pharmacists reported common infections frequently managed in the community pharmacies to include; malaria, typhoid, urinary tract infections, respiratory tract infections, fungal infections, viral infections and parasitic infections. These infections are summarized in Table 2. More than 90\% (110) community pharmacists reported that there has been an increase in the number of infections being managed in their pharmacies as shown in Table 3. 
Table 1. Demographic Parameters of the Community Pharmacists

\begin{tabular}{llcc}
\hline Demographic & & Number & Percentage \\
\hline Gender & Male & 57 & 46.7 \\
& Female & 65 & 53.3 \\
\hline Additional Qualification & B.Pharm & 71 & 58.2 \\
& M.Pharm/M.Sc & 47 & 38.5 \\
& Pharm.D. & 3 & 2.4 \\
& MBA & 1 & 0.8 \\
\hline Mean Age & 31.05 + 3.216 years, range 23-38 years \\
\hline Mean years of community & $4.08+1.497$ years, range 1- 10 years \\
pharmacy experience & \multicolumn{3}{l}{} \\
\hline Number of pharmacists based on & Oyo state & 72 \\
states & Akwa Ibom state & 50 & 41.0 \\
\hline
\end{tabular}

Key:

B. Pharm = Bachelor of Pharmacy

Pharm.D: Doctor of Pharmacy

M. Pharm: Master of Pharmacy

M. Sc: Master of Science

MBA: Masters in Business Administration

This shows that community pharmacists are highly accessible professionals and can provide treatment for minor ailments and infections. ${ }^{16}$

Pattern of infections seen at the pharmacy by the community pharmacists since COVID-19 The pharmacists reported malaria (81, $66.4 \%$ ), respiratory tract infections (40, $32.8 \%$ ) and sexually transmitted infections $(1,0.8 \%)$ as infections with the highest frequency seen in the pharmacy while 62 $(50.8 \%)$ and $2(1.6 \%)$ documented typhoid and urinary tract infections as the second most frequent infections treated in the pharmacy respectively. More than 40\% (50) reported that fungal infections was the third most frequent infections managed in their pharmacies while about 39\% (48) and more than $15 \%$ (19) stated that parasitic infections and viral infections were the lowest treated infections in their pharmacy. Further details can be found in Table 3.
In the community pharmacy setting, measures have been put in place such as hand washing before entering the pharmacy and maintenance of at least 1 meter distance between the patient and the pharmacist during consultations. However, this did not affect the reported number of cases as seen in this study. The majority of the community pharmacists reported that there has been an increase in the number of infections being treated at the pharmacy as compared to before COVID-19 started. This can be attributed to reduced healthcare services accessible to non COVID-19 patients in order to cater for increasing COVID-19 cases $^{17}$ as getting appointments has been reported to be more difficult as hospitals are trying to limit the number of patients in the healthcare facility to help curb the spread of the virus. The pharmacists reported malaria and respiratory tract infections as the highest cases of infections seen in the pharmacy during the COVID-19 era. This could be attributed to the rainy season which is usually 
Table 2. Infections Regularly Managed by the Community

\begin{tabular}{lcc}
\hline \multicolumn{1}{c}{ Infections } & $\begin{array}{c}\text { Frequency } \\
(\mathrm{N}=122)\end{array}$ & Percentage \\
\hline Malaria + Fungal + STIs + UTIs + Viral + Parasitic + RTIs & 2 & 1.6 \\
Malaria + Typhoid + Fungal + STIs + UTIs + Parasitic + RTIs & 7 & 5.7 \\
Malaria + Typhoid + Fungal + STIs + UTIs + RTIs & 2 & 1.6 \\
Malaria + Typhoid + Fungal + STIs + UTIs + Parasitic + Viral + RTIs & 107 & 87.9 \\
Malaria + Typhoid + Fungal + STIs + UTIs + Viral + RTIs & 1 & 0.8 \\
Malaria + Typhoid + Fungal + STIs + UTIs +Viral + Parasitic & 1 & 0.8 \\
Malaria + Typhoid + Fungal + UTIs + Viral + Parasitic + RTIs & 1 & 0.8 \\
Malaria + Typhoid + Fungal + UTIs + Parasitic + RTIs & 1 & 0.8 \\
\hline
\end{tabular}

Key:

STIs: Sexually transmitted infections

UTIs: Urinary tract infections

characterized with respiratory infections and malaria. However, the higher number of cases can also be linked with COVID-19 cases as some studies have reported COVID-19 patients coming down with co-infections and superinfections in Belgium ${ }^{18}$ and Morocco respectively. ${ }^{19}$ Although these patients were critically ill COVID-19 patients and it is difficult to confirm if the patients treated by the pharmacists in this study were COVID-19 patients.

Effect of COVID-19 on the treatment of other infections by community pharmacists

In this study, more than $96 \%$ (118) pharmacists reported that COVID-19 has affected the way they manage or treat other infections seen in their pharmacy. More details can be found in Table 4.

In this study, the majority of the pharmacists reported that the pandemic has affected the way treatment of other infections is being carried out in their pharmacies. This can be compared to other documented studies that COVID-19 has some impact on the management of non-communicable diseases such as $\mathrm{HIV}^{17}$, cancer ${ }^{20}$, and cardiovascular
RTIs: Respiratory tract infections

$\mathbf{N}$ : Number of study participants

diseases. ${ }^{21}$ Thus more studies should be carried out on the effect of the pandemic on the treatment/ management of infectious diseases.

A good number of the community pharmacists agreed to referring patients showing symptoms of COVID-19 and also ordering for the running of tests now more often for patients complaining of unusual symptoms. This is important as early detection of COVID-19 limits its spread and this has been linked to better clinical outcomes in several studies. $22-24$

A few pharmacists agreed to including of hydroxychloroquine, azithromycin and zinc to patients' medications for those showing similar symptoms of COVID-19. This could be due to mixed reports on the effectiveness and its association with less hospitalization and lower cases of death with patients being managed with the drug combination..$^{25,26}$

\section{Practical implications}

The results of this study imply that the pandemic has some form of effect on the treatment of other infections by community 


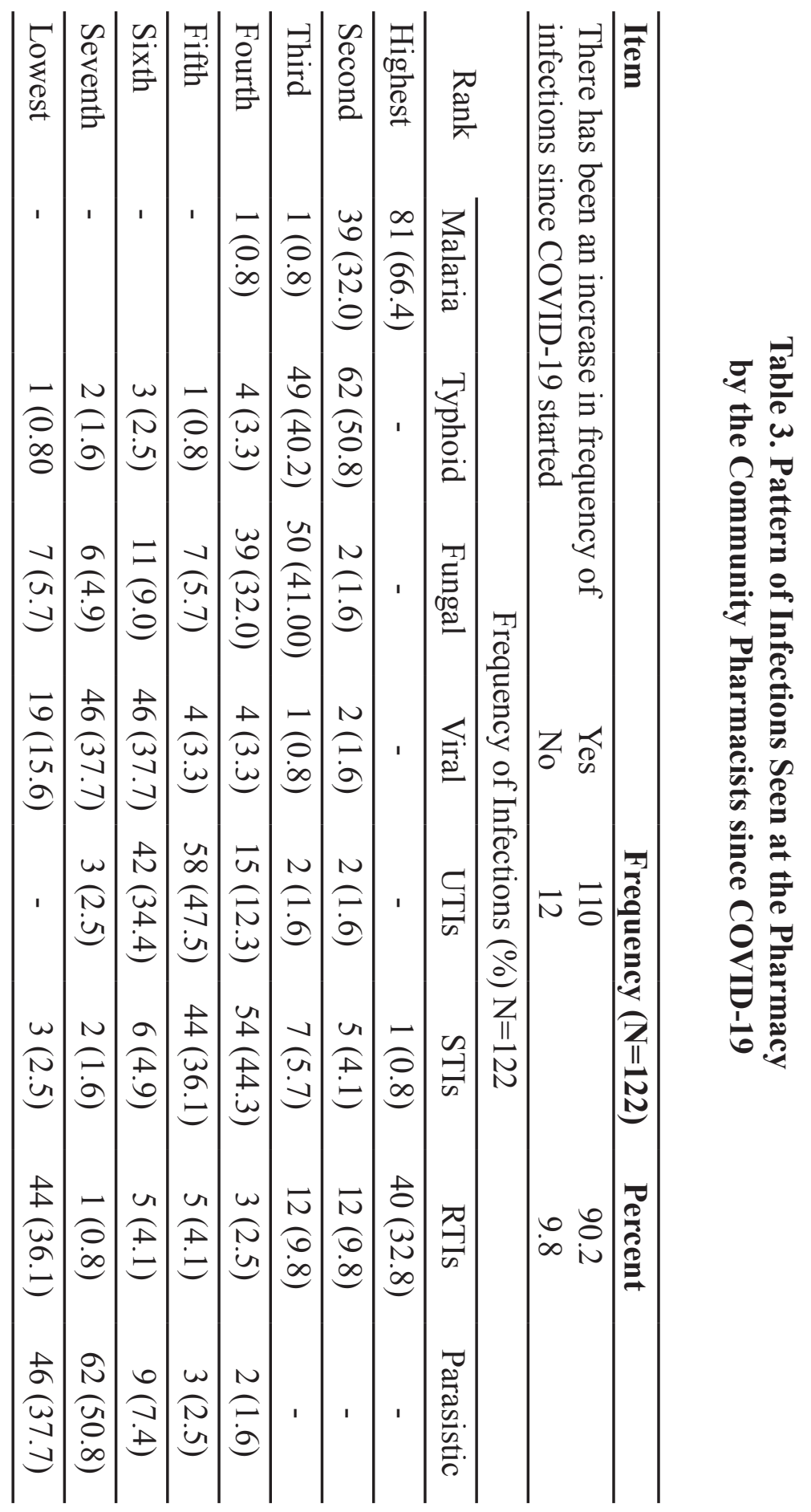

pharmacists and further studies are needed to evaluate this effect and the potential effect the pandemic can have on pharmacy practice.

\section{Limitations}

This study was carried out in two states where there are increased cases of COVID-19 and replicating the study in other states particularly states with lesser cases should be considered. Also, the relatively small sample size should be considered in the generalizability of the study results. 
Table 4. Effect of COVID-19 on the Treatment of other Infections by Community Pharmacists

\begin{tabular}{|c|c|c|c|c|c|}
\hline \multirow{3}{*}{$\begin{array}{l}\text { Item } \\
\text { COVID-19 has affected the way I manage } \\
\text { the infections seen in my pharmacy }\end{array}$} & & \multicolumn{2}{|c|}{ Frequency $(\mathrm{N}=122)$} & \multicolumn{2}{|l|}{ Percent } \\
\hline & Yes & 118 & & 96.7 & \\
\hline & No & 4 & & 3.3 & \\
\hline \multirow[b]{2}{*}{ Statements } & \multicolumn{4}{|c|}{ Responses $(\%) \mathrm{N}=122$} & \\
\hline & SA & $\mathrm{A}$ & $\mathrm{N}$ & $\mathrm{D}$ & SD \\
\hline $\begin{array}{l}\text { I refer patients with symptoms similar to } \\
\text { that of COVID-19 }\end{array}$ & $57(46.7)$ & $53(43.4)$ & $6(4.9)$ & $2(1.6)$ & $4(3.3)$ \\
\hline $\begin{array}{l}\text { I lose interest in treating patients complain- } \\
\text { ing of symptoms similar to COVID-19 for } \\
\text { fear of complications }\end{array}$ & $3(2.5)$ & $12(9.8)$ & $44(36.1)$ & $58(47.5)$ & $5(4.1)$ \\
\hline $\begin{array}{l}\text { COVID-19 has had no effect on the way I } \\
\text { manage other infections in my pharmacy }\end{array}$ & $3(2.5)$ & $7(5.7)$ & $5(4.1)$ & $23(18.9)$ & $84(68.9)$ \\
\hline $\begin{array}{l}\text { I order for the running of tests now more } \\
\text { often for patients complaining of unusual } \\
\text { symptoms since COVID-19 started }\end{array}$ & $83(68.0)$ & $30(24.6)$ & $6(4.9)$ & $3(2.5)$ & - \\
\hline $\begin{array}{l}\text { I usually include hydroxychloroquine, } \\
\text { azithromycin and zinc to patients' medica- } \\
\text { tions for those showing symptoms similar } \\
\text { to COVID-19 }\end{array}$ & $4(3.3)$ & $11(9.0)$ & $12(9.8)$ & $51(41.8)$ & $44(36.1)$ \\
\hline
\end{tabular}

\section{Conclusion}

This study shows that the COVID-19 pandemic has affected the way community pharmacists treat other infections in the community pharmacy setting. More studies are needed to explore the specific nature of this effect on specific infections. Studies with larger sample size in other parts of Nigeria especially areas with lesser COVID-19 cases should be explored.

\section{Acknowledgment}

We thank all the community pharmacists for their cooperation in the timely completion of this study.

\section{Funding}

None

\section{Conflict of Interest}

None declared
References

1. World Health Organization!. Coronavirus disease 2019 (COVID-19)!: situation report, 51. Available at: https://apps.who. int/iris/handle/10665/331475 (Accessed on June22, 2020)

2. Singh A, Gupta R, Ghosh A, Misra A. Diabetes in COVID-19: prevalence, pathophysiology, prognosis, and practical considerations. Diabetes and Metabolic Syndrome Clinical Research and Review. 2020;14(4):303-310

3. Sanyaolu A, Okorie C, Marinkovic A, Patidar R, Younis K, Desai P, Hosein Z, Padda I, Mangat J, Altaf M. Comorbidity and its Impact on Patients with COVID-19. SN Comprehensive Clinical Medicine. 2020; 25:1-8.

4. Rossi R, Socci V, Pacitti F, Di Lorenzo G, Di Marco A, Siracusano A, Rossi A. Mental Health Outcomes Among 
Frontline and Second-Line Health Care Workers During the Coronavirus Disease 2019 (COVID-19) Pandemic in Italy. JAMA Network Open 2020; 3(20):10185

5. Varshney M, Parel J, Raizada N, Sarin S. Initial psychological impact of COVID-19 and its correlates in Indian Community: An online (FEEL-COVID) survey. PLoS ONE 2020; 15(23):3874.

6. Talevi D, Socci V, Carai M, Carnaghi G, Faleri S, Trebbi E, Bernardo A, Capelli F, Pacitti F. Mental health outcomes of the CoVID-19 pandemic. Rivista di Psichiatria 2020; 55: 137-144.

7. Khetrapal S, Bhatia R. Impact of COVID-19 pandemic on healthcare system and sustainable Development Goal. Indian Journal of Medical Research 2020; 202(151):395-399

8. Shadmi E, Chen Y, Dourado I, Faran-Perach I, Furler J, Hangoma $\mathrm{P}$, Hanvoravongchai $\mathrm{P}$, Obando $\mathrm{C}$, Petrosyan V, Rao KD, Ruano AL, Shi L, de Souza LE, Spitzer-Shohat S, Sturgiss E, Suphanchaimat R, Uribe MV, Willems S. Health equity and COVID-19: global perspectives. International Journal of Equity Health. 2020;19(1):104.

9. Tsuyuki R, Beahm N, Okada H, Al Hamarneh Y. Pharmacists as accessible primary health care providers: Review of the evidence. Canadian Pharmacy Journal. 2018; 151(1):4-5.

10. Hedima E, Adeyemi M, Ikunaiye N. Community Pharmacists: On the frontline of health service against COVID-19 in LMICs. Research in Social and Administrative Pharmacy 2020; 17(20):30385.

11. Grant M, Geoghegan L, Arbyn M, Mohammed Z, McGuinness L, Clarke E. The prevalence of symptoms in 24,410 adults infected by the novel coronavirus (SARS-CoV-2; COVID-19): A systematic review and meta-analysis of 148 studies from 9 countries. PLoS ONE 2020; 15(6): 234765.

12. General Assembly of the World Medical Association. 2014 World Medical Association Declaration of Helsinki: ethical principles for medical research involving human subjects. Journal of the American College of Dentists 2020; 310(20): 2191-2194

13. Nigeria Center for Disease Control. Epicurve by state 2020. Available at: https://covid19.ncdc.gov.ng/state/ (Accessed on June 20, 2020)

14. Uyo | Location, Facts, \& Population Britannica. Available at: https://www. britannica.com/place/Uyo (Accessed June 20, 2020)

15. Local Governments in Ibadan. Available at: $\quad$ www.ibadanlanda.org/Local Government.html (Accessed June 20, 2020)

16. Brian O, Henry N. Community pharmacists and health promotion activities in the 21 st century; maximizing the expanded roles for universal health coverage and population health optimization. MedCrave Online Journal of Public Health. 2017;6(3):354-358.

17. Chenneville T, Gabbidon K, Hanson P, Holyfield C. The Impact of COVID-19 on HIV Treatment and Research: A Call to Action. International Journal of Environmental Research and Public Health 2020; 17(12):4548.

18. Verroken A, Scohy A, Gérard L, Wittebole X, Collienne C, Laterre P. Co-infections in COVID-19 critically ill and antibiotic management: A prospective cohort analysis. Critical Care 2020; 24(1): 410.

19. Benmalek R, Mechal H, Choukrallah H, Maaroufi A, Benouna E, Habbal R, Aissaoui O, Erragh A, Nssiri A, AlHarrar R. Bacterial co-infections and superinfections in COVID-19: A case report of right heart infective endocarditis 
and literature review. The Pan African Medical Journal 2020; 35(2): 40

20. Al-Quteimat O, Amer A. The Impact of the COVID-19 Pandemic on Cancer Patients. American Journal of Clinical Oncology. 2020;43(6):452-455.

21. Golemi M, Golemi L, Tafur A, Pursnani A. The Novel Coronavirus Disease (COVID-19) and Its Impact on Cardiovascular Disease. Cardiology in Review. 2020; 28(4):163-176.

22. Hashmi H, Asif H. Early Detection and Assessment of Covid-19. Frontiers in Medicine 2020; 7(311):1-9

23. Tang Y, Schmitz J, Persing D, Stratton C. Laboratory Diagnosis of COVID-19: Current Issues and Challenges. Journal of Clinical Microbiology 2020; 58(6):512520

24. Almazeedi S, Al-Youha S, Jamal M, AlHaddad M, Al-Muhaini A, Al-Ghimlas F, Al-Sabah S. Characteristics, risk factors and outcomes among the first consecutive 1096 patients diagnosed with COVID-19 in Kuwait. EClinical Medicine 2020; 24 (1000448): 1-9.

25. Carlucci P, Ahuja T, Petrilli C, Rajagopalan H, Jones S, Rahimian J. Hydroxychloroquine and azithromycin plus zinc vs hydroxychloroquine and azithromycin alone: Outcomes in hospitalized COVID-19 patients. MedRxiv 2020; 5 (2):1-6

26. Scholz M, Derwand R, Zelenko V. COVID-19 Outpatients - Early RiskStratified Treatment with Zinc Plus Low Dose Hydroxychloroquine and Azithromycin: A Retrospective Case Series Study. Preprints 2020; 7(25): 1-10 